\title{
Beyond the RMA: Survival Strategies for Small Defense Economies
}

\author{
Ron Matthews and Curie Maharani ${ }^{*}$
}

\section{Small is beautiful... But in Defense?}

Life was straightforward during the Cold War. There were the big guys in the bi-polar strategic stand-off - the United States and the Soviet Union - and there were the little guys: the Eastern European countries, such as Poland, Hungary, and Yugoslavia; Chile in Latin America; Spain in Southern Europe; Sweden in Scandinavia; Israel in the Middle East; and Singapore in the Far East. All these countries, big or small, capitalist or communist, possessed comprehensive and diversified defense industrial bases. However, times have changed, and in some senses they have changed dramatically. More than anything else, economics does not favor small countries. Previously, Cold War doctrine was premised on mass formations of artillery, main battle groups of tanks and combat aircraft located on the Central European front. In the twenty-first century, these formations have disappeared. Militaries have been transformed by the need to respond to new, emerging, asymmetrical threats arising anywhere across the globe, a shift that is captured under the umbrella term of the "Revolution in Military Affairs" (RMA). Contemporary doctrine focuses on high-intensity warfare, characterized by sophisticated defense systems, such as telemetry and cruise missiles, fiber optic technologies, sensors, modern telecommunication systems, "stealth" coatings of modern weapon platforms, light-weight composite materials, and the miniaturization of technologies in, for instance, unmanned aerial vehicles (UAVs).

Under this new RMA-driven doctrine, there is an emphasis on heavy-lift aircraft, such as Europe's A400M and the US's C-17, to rapidly respond to "hot" wars across the world. UAVs have been deployed on reconnaissance, surveillance, and intelligence duties, often acting as "shooters." Just as important, laser-guided precision munitions delivered by computer-programmed cruise missiles have proved highly effective in minimizing collateral damage, removing entirely the danger of losing aircraft crews. This "Revolution in Military Affairs," then, has transformed the architecture of battlefield weapon systems, representing a networked systems-of-systems model, linking simultaneously a networked family of space-based satellites, land-based weapons systems, and global communications systems. ${ }^{1}$

The RMA - or transformational warfare, as it is now often called - is a contentious subject, because it intellectualizes whether these dramatic changes in doctrine and technology represent discontinuous developments in military technology or whether

\footnotetext{
Ron Matthews is a Professor of Defense Economics at Cranfield University, U.K., and in the Institute of Defense and Strategic Studies (IDSS) at Nanyang Technological University, Singapore. Curie Maharani is a research scholar at IDSS, Singapore.

1 Ron Matthews and John Treddenick, Managing the Revolution in Military Affairs (New York: Palgrave, 2001).
} 
they are simply an extension of a long-run trend of evolutionary improvement in military-related technological change. Either way, such transformation has had a profound impact on the defense economies of all countries, but particularly those of small countries. Small countries do not have the critical mass to justify hugely expensive investments in defense research and development (R\&D), nor do they enjoy long-term production runs to leverage the high $R \& D$ costs associated with the development of new weapons systems. The challenge for small-country defense industries, then, is simply to survive. $^{2}$

As such, this article seeks to explore the particular challenges facing small countries in creating and sustaining defense industrial capacity, particularly in the highly competitive post-Cold War environment that has emerged. To begin, however, it is essential to come to an understanding of what defines a "small" defense economy. This is not an easy question to answer. Singapore, for instance, is viewed as a small country. This is certainly the case when it is compared to Indonesia; the latter has a huge archipelago and a population of 242 million, compared to the tiny island state of Singapore, with just 4.4 million people. Yet Singapore's defense budget is twice that of Indonesia. Thus, the notion of a defense economy is a relative concept that goes beyond issues of country size. It is a concept that is influenced by a potpourri of critical factors, such as research and development, scale, the possession of subcontractor networks, the levels of defense expenditure, and, increasingly, globalization and open defense trade. The concept is sufficiently slippery that, while the United Kingdom is recognized as a global military power, having a major defense industrial base, it is a defense industrial and technological minnow when compared to the United States.

\section{Defining Critical Mass}

Defense goods are not like refrigerators or color TVs. For most countries, armaments are an essential rather than a luxury good. Adam Smith regarded defense of the realm as the sovereign's highest priority, and for that reason defense is, arguably, the ultimate public good:

The first duty of the sovereign, that of protecting the society from the violence and invasion of other independent societies, can be performed only by means of a military force. But the expense both of preparing this military force in time of peace, and of employing it in times of war, is very different in the different states of society, in the different periods of improvement. ${ }^{3}$

Thus arms production is far too important to be subject to the commercial vagaries of the market. There is a practical problem with this argument, however: defense is expensive. Aside from the high cost of procurement, if arms production is left in the

2 For further elaboration on the problems facing small defense economies from a European perspective, see Wally Struys, "The Future of the Defense Firm in Small and Medium Countries," Defense and Peace Economics 15:6 (December 2004).

3 In Gavin Kennedy, Defense Economics (London: Unwin, 1983), quoting Adam Smith, An Inquiry into the Nature and Causes of the Wealth of Nations (Bondon: T. Nelson, 1852), 296. 
hands of government, the danger is that the defense economy will suffer from malaise, low productivity, inefficiency, and poor competitiveness. Thus, from a policy perspective, if defense is viewed as a public good, and arms are produced in the public sector, then the inevitable increased costs will be a burden that is borne by the taxpayers.

Efficiency in the provision of the defense is fundamentally important, but it presupposes that there is objectivity regarding the appropriate level of defense. However, this is an issue about which many people disagree. What "should" be the required level of defense expenditure? Should the level of analysis be in absolute or relative values? At any point in time, how much should be spent on the defense of one country as opposed to another? In theory, the answer to these questions depends on the existence and nature of the threat. Yet often there is no obvious, well-defined threat. The U.K., for instance, is not facing any imminent danger of invasion from any country, but in 2007 it spent nearly USD 60 billion on defense. ${ }^{4}$ The U.K., as with many other countries, rationalizes its defense expenditure not solely on the basis of homeland defense but on the broader grounds of protecting its national interests; the latter, for the British government, presumably includes the projection of force in Afghanistan and Iraq. Moreover, the cost of developing a defense capability is akin to the expense of maintaining an insurance policy: hopefully it will never need to be used, but it provides the confidence and stability necessary to proceed with everyday life.

Notwithstanding the above questions, it is clear that a country's overall defense expenditure should be linked to the purpose of its armed forces as well as to the rationale behind its military objectives. In broad terms, this is covered by a nation's defense policy. Often, the problem with such policy, however, is that it can be framed in vague and ambiguous terms. As a consequence, defense policy can often be ignored or circumvented. Worse still, some countries may have no formal defense policy. For instance, Malaysia's weapons procurement practices over the last two decades appear to have been based more on ad hoc political dictate than on any overarching defense policy. The case is similar in Thailand, where the acquisition of a Spanish aircraft carrier appears to bear absolutely no connection to the conventional military threats the country faces (the practice is likely to continue with the procurement plan of French submarines and Swedish JAS 39 Gripen fighters). ${ }^{5}$ Indonesia provides another example, where the 1996 purchase of thirty-nine aging ex-East German naval warships seemed incomprehensible at the time, borne out by the fact that today only fourteen ships from the overall procurement are still operable. ${ }^{6}$ In fact, the disconnection between Indonesia's defense policy and its procurement practices is legendary. Note, for example, Jakarta's 2003 purchase of four Russian Su-27SK and Su-30MK fighter jets.

4 SIPRI Yearbook 2007: Armaments, Disarmament, and International Security (New York: Oxford University Press, 2007).

5 "Editorial: Too Many Toys for the Boys," The Nation (29 November 2007).

6 "INFID Surati Kanselir Jerman Agar Hapus Hutang Kapal Perang Bekas," Antara (2 June 2007). 
The purchase was not only out of sync with Indonesia's defense policy, it did not even figure in the Indonesian MoD's annual defense procurement plan.?

In reality, then, defense policy may not be a good guide for determining the appropriate level of defense expenditure. Yet the fundamental question remains: how much should a country spend on defense? How much is enough? Is it sensible to determine the defense budget according to a country's population, its geographic size, or to the strength of its economy? In practice, defense economists have exhibited a preference for the latter variable. Perhaps unsurprisingly, the discipline of defense economics focuses on the relationship between defense and the economy, and is based on the presumption that military power is closely calibrated with economic strength. ${ }^{8}$

The nature of the relationship between defense expenditure and economic development takes the discussion to another level of analysis, focusing on the postulated "burden" that defense expenditures impose on a country's economy. The thesis is that, as military expenditure as a percentage of gross domestic product (GDP) rises, so does the opportunity cost or burden of defense. The proposition is straightforward, but proving it is altogether more difficult. Emile Benoit, the Belgian defense economist, first ignited the controversy with his seminal study of the 1962-63 border conflict between China and India. Benoit observed that India's national income rose continuously in the years following the war, leading him to conclude that the increase in India's defense spending had "caused" the subsequent rise in national income. ${ }^{9}$

It seems, then, according to this line of reasoning, that defense spending is cool: all that is required of a nation is to spend more on defense, and economic growth will ensue. However, this was a radical thesis, cutting across the grain of traditional thinking which viewed the costs of defense unequivocally as an economic burden on the state. It is based on the premise that employing scarce resources in relatively unproductive public-sector defense units "crowds out" other, more profitable uses, and contributes little to the welfare of society. Benoit stoked a fierce intellectual controversy that still rages today. Arguably, though, over the intervening years, the debate has come full circle. Now, the prevailing view once again leans toward the traditional paradigm - that is, that a negative trade-off exists between defense expenditure and economic growth. Yet, in the contemporary era, the impact of the RMA may undermine this view. Present defense economic trends, reflecting the extent and intensity of civil-military integration in the development and production of advanced weapons systems, suggest that Benoit's thesis may finally be coming of age. Rising defense spending may indeed be positively correlated with economic growth, though more research is required to prove this conclusively.

However, for most countries, big or small, true participation in the RMA remains financially out of reach. Cost precludes these countries from serious commitment to the

7 "Sukhoi didanai dari minyak," Rakyat Merdeka (3 September 2003).

8 See Paul Kennedy, The Rise and Fall of Great Powers: Economic Change and Military Conflict from 1500 to 2000 (New York: Vintage Books, 1989).

9 Emile Benoit, "Growth and Defense in Developing Countries," Economic Development and Cultural Change 26:2 (1978): 271-80. 
revolutionary "system of systems" model, and, as a consequence, defense and development remain awkward bedfellows. ${ }^{10}$ Defense continues to be viewed as a burden, signified by high ratios of defense spending to GDP. The World Bank, in addressing this issue, argued that the optimal level of defense spending should not exceed two percent of national income. ${ }^{11}$ There seems little rationale behind this position, however. As was argued earlier, defense expenditure is influenced by numerous national interests, changing threat perceptions, and the historical and cultural baggage of a country's evolution. Germany and Japan, for example, presently spend around 1 percent of GDP on defense, contrasting sharply with their militaristic lineage. Singapore, on the other hand - a small, recently independent state-spends 4.7 percent of its national income on defense, representing a higher defense burden than that borne by the United States. Therefore, the notion of an optimal ratio of defense spending to GDP is unhelpful, as only a cursory glance at the published percentages would attest.

The real policy issue should instead be focused on the nature of the relationship between military spending and GDP. The primary goal is to maximize growth in national income (the denominator in the ratio). If GDP growth can be maximized, then this will accommodate expansion in military expenditures (the numerator in the ratio). Significantly, any increase in defense spending under these conditions will occur with minimum impact on the overall percentage of the defense burden. Once again, this highlights the importance of the relation between economic growth and military spending. Japan, in particular, has used its understanding of this relationship to great effect over recent decades. Japan has substantially raised its defense expenditure in absolute values, year-on-year, due to dramatic increases in economic growth, but it has still maintained its one-percent ceiling of defense expenditure relative to national income, which is mandated by policy.

\section{Defense Economics and the Paradox of Smallness}

Classical economics focuses on the pristine intellectuality of industrial fragmentation, transparency, standardization, and smallness. This is the Smithian world of myriad buyers and sellers, free information flows, zero barriers to market entry/exit, product homogeneity, and minimal government intervention. It is a model of enduring appeal, reflecting the conceptual basis for the post-1980s global commercial revolution that usually is subsumed under the rubric of "globalization." The liberal economic crusade superseded the redundancy of Keynesian economics, sowing the seeds for the later disintegration of communism. It has taken seven decades to loosen the grip of the dead economic hand of Marxism, and with it the institutional suppression of competitiveness and innovation. However, once it happened, small business entities were, as before, at

${ }^{10}$ William A. Owens and Ed Offley, Lifting the Fog of War (New York: Farrar, Straus and Giroux, 2001).

11 Martin Sehlapelo, "The South African Strategic Defense Procurement Package and Economic Growth: Are They Mutually Exclusive?” African Security Review 11:4 (2002): 11924. 
the forefront of the emerging liberal policy-making agenda. This is a simplistic view of global economic transition because, while smallness has come back into vogue, bigness and scale often appear to be the winners in "free" market economics. In practice, it appears that capitalism has some inherent contradictions.

The economics of communism, particularly of the Soviet Union and China, provide the contrast to classical thought. Communist economic dogma promoted bigness, specialization, and standardization in the search for economies of scale and cost reduction (the latter being of particular importance in capital-poor economies). However, the benefit of scale in the Soviet and Chinese development models was eroded by the lack of backward linkages with small, mature, specialized, and diversified subcontractors that had not had the time to evolve. The communist model rejected any ideological commitment to Smith's notion of "perfect" competition, and its implied assumption of large numbers of small businesses battling it out for scarce resources. Perfect competition was viewed as a theoretical construct that bore no connection to the economics of the real world.

Contemporary markets, by definition, are imperfect markets, connoting brand differentiation, barriers to entry, patents to protect intellectual property rights, and high levels of government intervention. Capitalism is inappropriate to the development of emerging economies because it encourages resource waste through production duplication. In turn, this leads to capacity underutilization, with demand limited by the extent of the immature market. Moreover, the transmogrification of the Darwinian principle of "survival of the fittest" from the biological to the economic domain means that there could be no long-term equilibrium under the perfect competition model. Rather, through organic growth and/or mergers and acquisitions, efficient small firms would evolve into super-efficient big firms. This is the natural order: the contemporary economic world of imperfect competition. Even the dominance of the World Trade Organization, with its policy emphasis firmly focused on trade liberalization, is regularly criticized as having fostered a globalized economic and financial environment where big multinational companies have benefited disproportionately from the proliferation of free trade opportunities.

With the growing importance of big organizations (and, by logical extension, big economies), the economic demise of relatively small micro- and macro-level operations would be the natural expectation. Paradoxically, however, this has not been the case. Flexibility, adaptability, efficiency, and innovation symbolize the approach of small organizations. Significantly, they are responsive to market movements and, working in concert with customers, have the potential to drive innovation through higher levels of refined specialization. Similarly, small economies are able to exploit the economic advantages of specialization and technological clustering that are engendered through the close proximity of suppliers and customers, and are more likely to create a greater sense of national identity and cultural affinity that derives naturally from small behavioral contexts. It comes as no surprise, therefore, that the prestigious World Economic Forum (WEF), in its Global Competitiveness Index, regularly shows a majority of small nations at the head of its annual rankings. Table 1 illustrates the 2007 rankings, and lists six small countries (Switzerland, Denmark, Sweden, Finland, 
Singapore, and the Netherlands) among the top ten most competitive nations in the world. The WEF country rankings are calculated by reference to the aggregation of a multitude of weighted politico-economic metrics, including capital market efficiency, human capital quality, macroeconomic performance, and the positive impact of science and technology policy on the national economy. Many of these factors require interventionist government policy and the promotion of stakeholder partnerships to support the development of a competitive economy. Through the adoption of such policies, small countries are likely to enjoy greater competitiveness. Also, perhaps inevitably, small economies are outward-oriented in order to capture scale effects and compensate for constrained internal demand.

Table 1: WEF Global Competitiveness Index ${ }^{12}$

\begin{tabular}{lccc}
\hline \multicolumn{1}{c}{ Country } & \multicolumn{2}{c}{ GCI 2007-08 } & GCI 2006-07 \\
& Rank & Score & 1 \\
\hline United States & 1 & 5.67 & 4 \\
\hline Switzerland & 2 & 5.62 & 3 \\
\hline Denmark & 3 & 5.55 & 9 \\
\hline Sweden & 4 & 5.54 & 7 \\
\hline Germany & 5 & 5.51 & 6 \\
\hline Finland & 6 & 5.49 & 8 \\
\hline Singapore & 7 & 5.45 & 5 \\
\hline Japan & 8 & 5.43 & 2 \\
\hline United Kingdom & 9 & 5.41 & 11 \\
\hline Netherlands & 10 & 5.40 & \\
\hline
\end{tabular}

\section{Conflicting Challenges of Small Defense Economies}

A comparison between defense and commercial markets will highlight several fundamental differences between the two. The defense economy is located at the extreme opposite end of the spectrum from perfect competition, and, indeed, is even far removed from the more pragmatic notion of contestable markets. In defense markets, governments aggressively intervene to control both supply and demand; they are characterized by secrecy, regulation, and often high barriers to entry. This is an environment where national sovereignty repulses the forces of globalization. Oligopolistic

12 Source: Michael E. Porter, Klaus Schwab, and Xavier Sala-i-Martin, eds., The Global Competitiveness Report 2007-2008 (New York: Palgrave Macmillan, 2007). 
market structures dominate, with preferential access to finance, acting to further distort resource allocation. The prevalence of defense offsets, moreover, acts as a serious impediment to product and price signals, thus undermining the efficacy of classical market processes. Such considerations lead to the judgment that a defense "market" does not in fact exist. How can there be a market if product price is both unreflective of the forces of supply and demand and is often simply irrelevant?

In the twenty-first century defense milieu, big defense economies dominate, but small ones can survive. Table 2 lists groups of selected defense economies: first, there are the big first-tier defense economies, such as the U.S., U.K., France, China, and India; then there are medium-sized, second-tier defense economies, including Australia, Canada, and Brazil; finally, there are the third-tier group of defense economies, such as Switzerland, Bulgaria, Singapore, Sweden, and Israel. Inclusion into one or other of the three tiers is based on the value of national defense spending. While the logic of categorizing the size of a defense economy on this basis is arbitrary, there can be little dispute that it accurately identifies the first-tier defense economies, equating, as they do, to the advanced industrialized nations. India may stand out as an anomaly, but there have been recent dramatic increases in its defense spending, driven by high levels of economic growth. Warships, land systems, and advanced combat aircraft are licenseproduced, and joint development and production of missile systems are successfully underway, including the Indo-Russian Brahmos missile. ${ }^{13}$ The second-tier defense economies fall into the USD 10-20 billion value segment. The third-tier defense economies are grouped below the threshold of USD 10 billion in annual defense spending, based on what appears to be a discernible expenditure gap between the small defense economies and the much higher defense expenditure levels of the second-tier defense economies.

Table 2 demonstrates vividly that the United States has the world's dominant defense economy, with a 2006 defense expenditure of USD 535 billion. ${ }^{14}$ This level of defense spending exceeds the rest of the world's combined expenditure on defense. Hence, all countries are small by reference to U.S. military expenditure, including the advanced European defense economies. Table 2 also shows that the U.S. has the world's biggest economy; the biggest population among advanced industrialized countries; the third biggest armed forces, after China and India; and the greatest defense expenditure per capita. Also, as a percentage of its huge economy, the U.S. defense burden is high, but not as high as Israel, which at 9.7 percent reflects a country that is on an almost continuous wartime economic footing. Singapore has the second-highest defense burden, at 4.7 percent. This small country accords a high priority to defense, not least because, as an island state, with a population that is composed of 90 percent ethic Chinese Singaporeans, it sees itself encircled by the Islamic countries of Malaysia and Indonesia.

13 Manjeet S. Pardesi and Ron Matthews, "India's Tortuous Road to Defense Industrial Selfreliance," Defense and Security Analysis 23:4 (December 2007): 419-38.

14 By 2007, U.S. defense spending had risen to USD 635 billion, including incremental increases in spending, principally due to the conflicts in Afghanistan and Iraq. 
Table 2: Ranking of Selected Defense Economies by Military Expenditure (MILEX), $2006^{15}$

Country

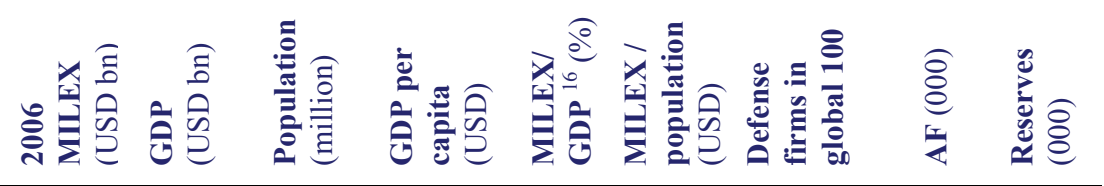

First Tier: >USD 20 billion

\begin{tabular}{lrrrrrrrrr}
\hline U.S. & 535.0 & 13,200 & 300.0 & 44,394 & 4.1 & 1783 & 45 & 1,500 & 974 \\
\hline U.K. & 55.1 & 2,430 & 60.6 & 40,223 & 2.7 & 909 & 11 & 191 & 199 \\
\hline France & 45.3 & 2,270 & 60.9 & 37,360 & 2.5 & 744 & 11 & 255 & 22 \\
\hline Germany & 35.7 & 2,970 & 82.4 & 36,118 & 1.4 & 433 & 8 & 246 & 162 \\
\hline China & 35.5 & 2,620 & $1,313.0$ & 2,000 & 2.0 & 27 & - & 2,255 & 800 \\
\hline Russia & 24.9 & 1,670 & 142.0 & 11,790 & 4.1 & 175 & 9 & 1,027 & 20,000 \\
\hline India & 22.3 & 839 & $1,112.0$ & 755 & 2.8 & 20 & 3 & 1,216 & 1,155 \\
\hline
\end{tabular}

Second Tier: > USD 10 billion

\begin{tabular}{lrrrrrrrrr}
\hline Brazil & 16.4 & 969 & 188.0 & 5,150 & 1.6 & 87 & 1 & 288 & 1,340 \\
\hline Australia & 15.1 & 746 & 20.0 & 36,973 & 1.8 & 755 & 3 & 52 & 19 \\
\hline Canada & 14.1 & 1,328 & 33.0 & 40,128 & 1.1 & 427 & 1 & 63 & 37 \\
\hline
\end{tabular}

Third Tier: <USD 10 billion

\begin{tabular}{lrrrrrrrrr}
\hline Netherlands & 9.8 & 681 & 16.5 & 41,280 & 1.5 & 606 & - & 53 & 32 \\
\hline Israel & 7.7 & 142 & 6.3 & 22,387 & 9.7 & 1,222 & 4 & 168 & 408 \\
\hline Singapore & 6.4 & 132 & 4.5 & 29,351 & 4.7 & 1422 & 1 & 73 & 313 \\
\hline Sweden & 5.9 & 387 & 9.0 & 42,885 & 1.5 & 656 & 1 & 28 & 262 \\
\hline Norway & 4.8 & 328 & 4.6 & 71,232 & 1.7 & 1043 & 1 & 23 & 210 \\
\hline Greece & 4.7 & 237 & 10.7 & 22,191 & 4.1 & 445 & - & 147 & 289 \\
\hline Switzerland & 3.6 & 389 & 7.5 & 51,759 & 1.0 & 480 & 1 & 4 & 210 \\
\hline Malaysia & 3.1 & 143 & 24.3 & 5,871 & 2.4 & 127 & - & 109 & 52 \\
\hline Indonesia & 2.6 & 346 & 232.0 & 1,490 & 1.2 & 11 & - & 302 & 400 \\
\hline $\begin{array}{l}\text { Czech Re- } \\
\text { public }\end{array}$ & 2.5 & 146 & 10.2 & 14,227 & 1.8 & 248 & - & 25 & - \\
\hline Bulgaria & 0.7 & 29.5 & 7.3 & 4,000 & 2.4 & 101 & - & 51 & 303 \\
\hline
\end{tabular}

15 Sources: SIPRI Yearbook 2007 (New York: Oxford University Press, 2007); Military Balance 2007 (London: Routledge, 2007).

16 GDP figures are from 2005. 
Singapore and Israel, respectively, also have the second- and third-highest defense spend per capita, after the U.S. Both countries have relatively small population bases, and, therefore, emphasize technology "multipliers" through the deployment of sophisticated weapons systems. This policy emphasis on a high-technology defense posture compensates for the relatively small size of their active armed forces personnel. A further compensatory feature of the small size of the active Singaporean and Israeli Armed Forces is the importance attached to reservists, with these countries respectively holding 408,000 and 313,000 reservists. Other small countries, such as Switzerland, Sweden, Norway, Bulgaria and Greece, also possess high numbers of military reservists; hence, this is not a phenomenon isolated to Singapore and Israel.

Table 3 details the arms trading performance of the same three tiers of countries across the extended period from 2002-06. The countries are ranked according to defense export value, and those leading the list are the United States, Russia, Germany, the United Kingdom, France, the Netherlands, and China. By contrast, the major arms importing states are China, India, Greece, Australia, and Israel. This leading group of arms importers includes both big and small defense economies alike. The high levels of Chinese and Indian arms imports reflect both countries' efforts to modernize their military inventories. However, the ultimate aim for both states to indigenize defense industry, partially in the case of India and comprehensively for China. If a low value of arms imports is interpreted as a proxy for high indigenous defense industrial capacity, then Russia, with just USD 4 million worth of imports, possesses what appears to be the world's most self-sufficient defense economy. France is ranked second in terms of self-sufficiency, having just USD 309 million worth of arms imports.

Russia has the biggest arms trading surplus, exceeding USD 30 billion. Then come the large defense economies of France, Germany, and the U.K., but ranked sixth, seventh, and eighth are three small nations: the Netherlands, Sweden, and Switzerland. The ranking of these small defense economies in the global top ten of countries having an arms trade surplus signifies that small defense economies can achieve competitiveness in the international arms market.

\section{Small Defense Economies and Defense Industrial Strategy}

Significant defense-industrial development does not happen overnight. It is normally the result of decades, if not generations, of accumulated investment, including the creation of layers of specialized skill and capacity within a nation's workforce. It is relatively easy for industrializing states to attract foreign direct investment, but the difficulties associated with the transplantation of sophisticated, "alien" production processes hardly guarantee the evolution of indigenous design, development, and production capabilities. If this were the case, then India would by now possess a self-sufficient defense industry, but it does not. Decades of licensed production of Soviet and then Russian weapons systems has allowed India to locally produce foreign weapons systems, but it is still dependent on overseas supply for the next generation of armaments. However, India is interpreted as possessing a first-tier defense economy, and with rising defense expenditure and local defense R\&D capability and expanding in- 
Table 3: International Arms Trade, 2002-06 ${ }^{17}$

\begin{tabular}{lccrrr}
\hline Country & $\begin{array}{c}\text { Global } \\
\text { Rank }\end{array}$ & $\begin{array}{c}\text { Arms } \\
\text { Export } \\
\text { (US\$m) }\end{array}$ & $\begin{array}{c}\text { Global } \\
\text { Rank }\end{array}$ & $\begin{array}{c}\text { Arms } \\
\text { Imports } \\
\text { (US\$m) }\end{array}$ & $\begin{array}{c}\text { Arms Trade } \\
\text { Balances } \\
\text { (US\$m) }\end{array}$ \\
\hline U.S. & 1 & 32,128 & 11 & 2,276 & 29,852 \\
\hline Russia & 2 & 30,764 & 121 & 4 & 30,760 \\
\hline Germany & 3 & 9,164 & 24 & 1,087 & 8,077 \\
\hline France & 4 & 8,888 & 55 & 309 & 8,579 \\
\hline U.K. & 5 & 4,488 & 13 & 2,131 & 2,357 \\
\hline Netherlands & 6 & 3,215 & 29 & 932 & 2,283 \\
\hline China & 8 & 2,134 & 1 & 14,609 & $(12,475)$ \\
\hline Sweden & 9 & 1,960 & 49 & 371 & 1,589 \\
\hline Israel & 10 & 1,673 & 10 & 3,457 & $(1,784)$ \\
\hline Canada & 13 & 1,186 & 26 & 1,039 & 149 \\
\hline Switzerland & 14 & 759 & 42 & 550 & 209 \\
\hline Norway & 17 & 267 & 37 & 606 & $(339)$ \\
\hline Czech Republic & 23 & 202 & 32 & 845 & $(643)$ \\
\hline Brazil & 26 & 144 & 33 & 826 & $(682)$ \\
\hline Australia & 27 & 126 & 6 & 3,461 & $(3,335)$ \\
\hline Indonesia & 32 & 90 & 36 & 654 & $(564)$ \\
\hline Bulgaria & 33 & 80 & 62 & 192 & $(112)$ \\
\hline Greece & 34 & 76 & 3 & 7,243 & $(7167)$ \\
\hline Singapore & 36 & 71 & 20 & 1,295 & $(1,224)$ \\
\hline India & 41 & 41 & 2 & 10,152 & $(10,111)$ \\
\hline & & & & & \\
\hline
\end{tabular}

ternational cooperation, enhanced defense-industrial competence and self-reliance is anticipated.

Countries seek local defense capacity for strategic, economic, and political reasons. Strategically, sovereignty of supply is sought because of fears that overseas supplier countries might impose arms embargoes. Economics is also an important motivation, because local jobs and higher skills are generated, with investment multipliers from major defense programs propelling the economy forward to higher levels of growth. Finally, from a political perspective, domestic defense production raises a country's

17 Source: SIPRI Yearbook 2007 (New York: Oxford University Press, 2007); USD constant 1990 prices (2002-06). 
power profile (and hence its status) in regional and even global fora. Few industrializing states have no defense industrial capacity, and, all countries, big or small, employ the above rationale for justifying local production. The development challenge for latecomers to the industrialization party, though, is how to initiate, foster, and-most crucially - sustain the process of defense industrialization. Countries deciding whether or not to promote industrial defense capability have only four main policy options:

1.Relinquish defense ambitions. Although this may appear a radical option, there are countries that have chosen to dispense with the idea of military capability altogether, and hence the need for defense spending. Costa Rica, in Central America, is one such country. Also, New Zealand provides an example of a country that followed this route part way, determining some years back that it made little economic or strategic sense to maintain a combat aircraft wing. This capability was thus abandoned.

2. Off-the-shelf (OTS) purchase. OTS purchases possess the advantage of low-cost acquisition. Even though the procurement order may be low in volume, costs will be minimized, as overseas suppliers will already have the tooling in place, with R\&D amortized through production for the host country's armed forces, and possibly sales to other countries as well. Delivery will also take place more quickly, and this may be attractive for strategic reasons - e.g., perhaps in a situation where regional tensions have recently intensified. The purchasing country's armed forces are normally content with this option, as they seek the best military materiel available, and that normally means US, Russian, or European equipment.

3. Build a non-dependent defense industry. In practice, this is no longer a viable option. The policy goal of developing states is comprehensive self-sufficiency, and this goes well beyond the initial and relatively easy first step of creating facilities to manufacture small arms and ordnance. RMA technologies, for instance, demand high degrees of precision engineering skills across a broad range of commercial high technology areas, as well as the possession of sophisticated R\&D, project management, and systems integration expertise in the defense industrial environment. Only a few countries possess the financial and technological resources to seriously commit to this option.

4.Defense technology access through offsets. This option provides a more measured approach to domestic defense industrialization. It facilitates the build-up of defense capacity through a staged process of modular equipment assembly through licensed production, involving progressively more intensive local production of components and sub-assemblies over time. Ultimately, via investments in domestic R\&D capability, local incipient defense companies will partner in regional and global defense-industrial consortia and strategic alliances, eventually reaching the final and most difficult stage of defense-industrial self-reliance. This option requires that direct offsets are negotiated and agreed at the time that arms procurement contracts are signed. The expectation of the purchasing government is that the resulting technology transfer package will provide the hard and soft technologies needed to effect sustainable defense industrialization. 
For small countries seeking to develop defense industrial capacity, the fourth option listed above represents the most realistic choice. Small-country governments recognize that higher costs are necessitated by investments into local tooling and production infrastructure, particularly given the small scales of output required. Accordingly, state policymakers, such as those in Sweden and the Netherlands, will devise proactive defense-industrial strategies to defray the inevitable high costs arising from licensed production. These countries' strategies are aimed at promoting defense exports to ensure that foreign demand raises output volumes in their constrained national defense markets. However, for a defense export strategy to be effective, small countries will need to specialize in niche, high-value-added sectors. If successful, this will then allow them market entry as subcontractors into the global supply networks of the major defense contractors. The development of specialized producers of high technology products can be assisted via deliberate government policies to foster a local industrial environment that is able to benefit from rich technological synergies. These will arise from the formation of industrial clusters focused towards selected specialized fields. The clusters will comprise companies engaged in both horizontal (primes and sub-primes) and vertical competition (value chains). They may also include partnerships with university engineering and information technology centers of excellence, and foreign defense firms seeking to establish and develop a presence in the nascent local market.

Even with appropriate strategies in place, small countries are often over-ambitious in what they believe can be achieved through defense offsets. Much depends on the extent and quality of technology transfer. The technology transferor needs to be committed to the view that mutual benefit will only come about through the development of a long-term contractual relationship. Equally, the transferee must be patient, but supportive, rolling out an integrated development plan that will bind together defense procurement and industrial planning in the country's broader economic and science and technology plans. However, neither defense nor commercial industry will be able to compete and prosper in the absence of $\mathrm{R} \& \mathrm{D}$ capacity. Investment alone will be insufficient. Rather, a research-oriented culture must evolve through prioritizing the development of a strong, dedicated, and highly qualified cadre of specialized engineers, scientists, and technology experts.

Offsets, focused on licensed production, will be effective, but only if the long-term goal is the development of a sustainable competitive advantage. In the short term, this undoubtedly means government sponsorship and subsidy. In the long term, through the commitment of all stakeholders, niche competitiveness can be achieved. The defense export performance of the Netherlands, Sweden, Israel, Switzerland, and even (to a lesser degree) Bulgaria are testament to this fact.

\section{Conclusion}

Small defense economies can survive and, indeed, prosper in the radically transformed post-Cold War international defense environment. Tighter defense budgets, global defense-industrial consolidation, increased regional arms collaboration, and international joint development and production ventures have all worked to alter the defense land- 
scape, but the attendant processes of globalization have created opportunities for small-country defense manufacturers to participate as specialized subcontractors. Of primary importance in the realm of policy, however, is arriving at a clear definition of "small defense economies." The data are confusing in this respect. Singapore, for instance, is far smaller than Indonesia, but has a defense budget that is twice as large, spends 129 times as much on defense per capita, and possesses a far bigger and more capable defense industry.

What is not known, of course, is the social and private cost of small-country defense industrialization efforts. These costs are likely to be high, but may be defrayed to some extent by civil-military integration of products and processes and foreign sales opportunities. Pursuit of both civil-military integration and defense exports has the potential of raising production scale and reducing unit cost, leading to a virtuous circle of defense-industrial endeavor. Defense offsets may offer a rapid route to the laying of indigenous defense-industrial foundations, enabling small countries to leap-frog over certain technological stages. However, whether such development is realized or not depends on the breadth and depth of the small country's capabilities to absorb new technologies. Ensuring the evolution of such capability will be the responsibility of the government, in concert with local defense-industrial stakeholders and, increasingly, with overseas original equipment manufacturers (OEMs). Small economies represent both a dominant proportion of the top ten states in the WEF's global competitiveness rankings and a significant minority of the top ten arms-trading nations. While further microeconomic research needs to be undertaken to verify and account for the success of small defense economies, there are tentative grounds for believing that small can be beautiful. 
SUMMER 2008

\section{Bibliography}

Benoit, Emile. "Growth and Defense in Developing Countries." Economic Development and Cultural Change 26, no. 2 (1978): 271-80.

Kennedy, Paul. The Rise and Fall of Great Powers: Economic Change and Military Conflict from 1500 to 2000. New York: Vintage Books, 1989.

Matthews, Ron, and John Treddenick. Managing the Revolution in Military Affairs . New York: Palgrave, 2001.

Owens, William A., and Ed Offley. Lifting the Fog of War . New York: Farrar, Straus and Giroux, 2001.

Pardesi, Manjeet S., and Ron Matthews. "India's Tortuous Road to Defense Industrial Selfreliance." Defense and Security Analysis 23, no. 4 (2007): 419-38.

Sehlapelo, Martin. "The South African Strategic Defense Procurement Package and Economic Growth: Are They Mutually Exclusive?" African Security Review 11, no. 4 (2002): 119-24.

Smith, Adam. An Inquiry into the Nature and Causes of the Wealth of Nations . Bondon: T. Nelson, 1852.

Struys, Wally. "The Future of the Defense Firm in Small and Medium Countries." Defense and Peace Economics 15, no. 6 (2004). 